\title{
ANÁLISE E INTERPRETAÇÃO DE MATERIAIS CERÂMICOS DO SÍTIO ARQUEOLÓGICO ROSÁRIO, GUAÍRA - SÃO PAULO
}

Fernando Henrique Ferreira de Oliveira; Neide Barrocá Faccio, Juliana Aparecida Rocha Luz

Universidade Estadual Paulista - FCT/UNESP - Presidente Prudente - SP. E-mail: fer henrique15@hotmail.com; nfaccio@terra.com.br

\section{RESUMO}

Este artigo tem como objetivo discutir os resultados da curadoria e análise dos materiais cerâmicos provenientes do Sítio Arqueológico Rosário, localizado no Município de Guaíra, SP. Buscamos relacionar os elementos da cultura material com os aspectos físicos do meio ambiente impresso na paisagem arqueológica. A pesquisa objetivou entender a relação entre os elementos da cultura material com a paisagem, unidade de estudo compreendida pela relação dialética entre elementos naturais e humanos. Assim, analisando os materiais cerâmicos pelo enfoque da cadeia operatória e do estudo da paisagem, apresentamos contribuições para o conhecimento das ocupações pretéritas no Norte do Estado de São Paulo.

Palavras-chave: Sistema de Povoamento - Aratu-Sapucaí - Sítio Arqueológico.

\section{ANALYSIS AND INTERPRETATION OF CERAMICS FROM ROSÁRIO ARCHAEOLOGICAL SITE, GUAÍRA - SÃO PAULO}

\begin{abstract}
The objective of this paper is to discuss the results of the curatorship and analysis of ceramics from Rosário Archaeological Site, situated in Guaíra, state of São Paulo. We sought to relate the elements of archaeological culture with the physical aspects of the environment present in such archeological landscape. The research aimed to understand the relation between the elements of the archaeological culture and the landscape, unit of study comprehended through the dialectical relation between natural elements and humans. Thus, analyzing the ceramics through operational chain and study of the landscape, we add contributions to the knowledge of the past occupations in the North of São Paulo State.
\end{abstract}

Keywords: Settlement System - Aratu-Sapucaí - Archaeologica 
INTRODUÇÃO

A cerâmica indígena, quando estudada em seu contexto paisagístico constitui um importante elemento para a compreensão do sistema regional de povoamento de grupos agricultores indígenas. Esta pesquisa apresenta um estudo sobre a cerâmica do Sítio Arqueológico Rosário, bem como a inserção desse material na paisagem.

No entorno da área do Sítio Rosário estão localizados outros 13 sítios arqueológicos: Guaíra, Bela Vista do Jacaré,
Água Azul, Água Azul II, Santana do Figueirão, Santana do Figueirão II, Vassoural São José, Cervo, Capão Escuro, Nova Índia, Santo Antônio do Lageado e Balsamina. São sítios líticos e lito-cerâmicos que se encontram relativamente próximos uns dos outros, à distância média de $21 \mathrm{~km}$. Estão localizados nos Municípios de Guaíra, Miguelópolis e Barretos/ SP, nas Bacias hidrográficas dos Rios Pardo/Grande e Sapucaí-Mirim Grande. A localização dos municípios onde se encontram os sítios arqueológicos pode ser observada na figura 1.

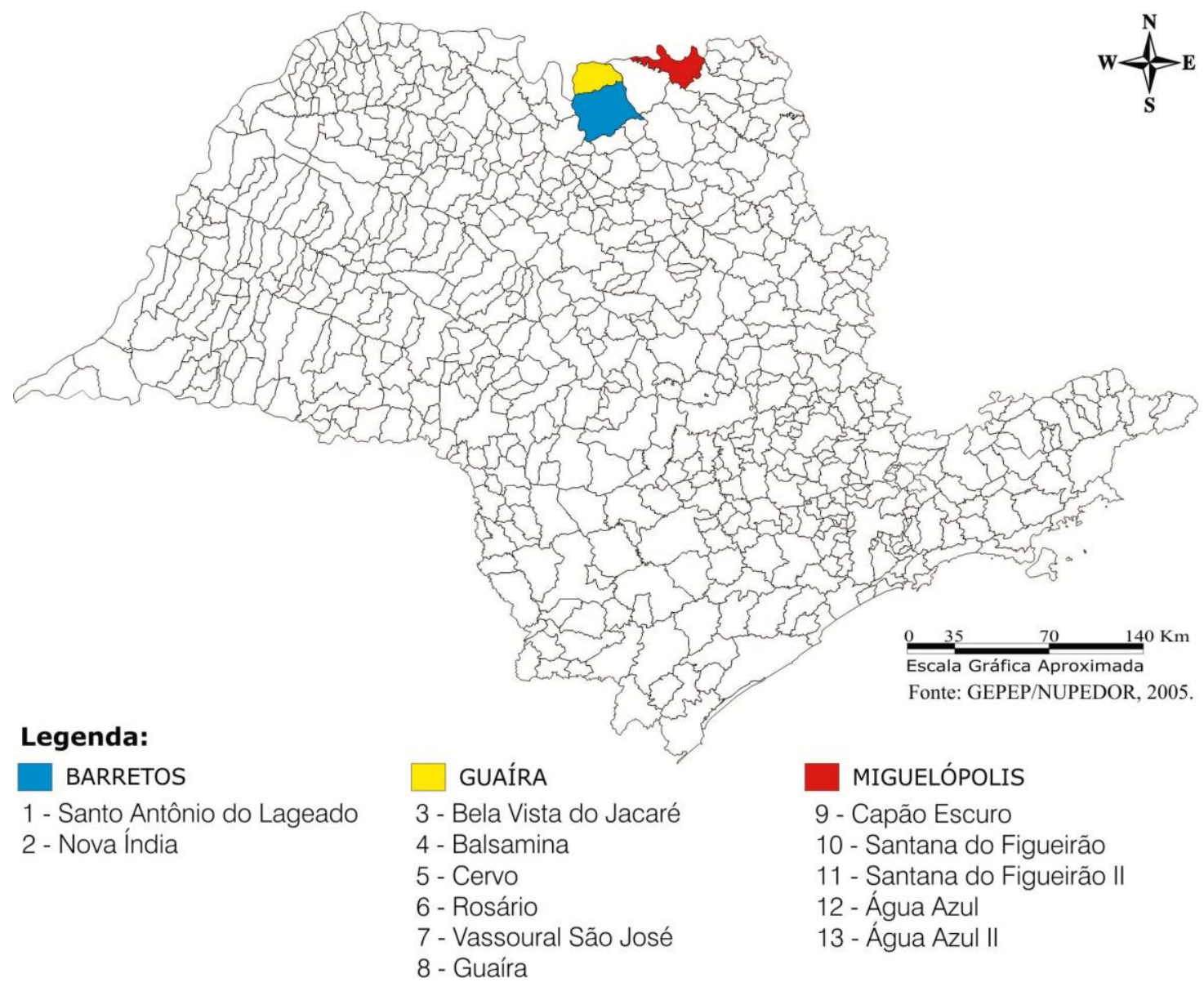

Figura 1. Localização dos sítios arqueológicos no norte do Estado de São Paulo e nos municípios de origem. 


\section{REFERENCIAL TEÓRICO}

Este trabalho é norteado pela arqueologia, ciência que tem por objetivo compreender os estabelecimentos humanos pretéritos, com base na análise da paisagem e dos elementos da cultura material, reconstituindo a relação do homem com o meio ambiente, além de seus hábitos alimentares, culturais e tecnológicos.

Segundo Renfrew e Bahn (2007):

la arqueología se interessa em el conocimiento global de la experiencia humana em el passado: como se organizaba la gente em grupos sociales y cómo explotaba el entorno; que comían, hacían y creían; como se comunicaban y por qué cambiaron sus sociedades (RENFREW; BAHN, 2007, p. 18).

Renfrew e Bahn (2007) escrevem que a história da arqueologia é marcada por uma história de ideias e questionamentos que dão corpo à teoria, pelo desenvolvimento dos métodos e técnicas de investigação e, por fim, uma história dos descobrimentos em campo. Nesse sentido, as teorias e os métodos foram se desenvolvendo até sua sistematização como disciplina. Nesse contexto, Renfrew e Bahn (2007) e Robrahn-González (1999/2000) colocam que a arqueologia se desenvolveu em três períodos: especulativo (1492-1840); descritivo-classificatório (1840 -1914) e

histórico-classificatório (1914-1960).

Em relação à sistematização da arqueologia moderna Renfrew e Bahn (2007) afirmam que:

La história de la arqueologia es, por tanto, una historia de ideias, métodos $y$ descubrimientos. La arqueologia moderna tuvo su origem em el siglo XIX, com la aceptácion de tres conceptos clave: la gran antiguedad de la humanidad, el principio evolucionista de Darwin y el Sistema de las Tres Edades para la clasificación de la cultura material (RENFREW; BAHN, 2007, p. 42).

Para Trigger (2004):

A arqueologia é uma ciência social no sentido que ela procura explicar o que aconteceu a um grupo específico de seres humanos no passado e fazer generalizações a respeito do processo de mudança cultural. Porém, ao contrário dos etnólogos, dos geógrafos, dos sociólogos, dos cientistas políticos e dos economistas os arqueólogos não podem observar o comportamento da população que eles estudam; ao contrário dos historiadores, também não têm, na maioria dos casos, acesso direto ao pensamento dessa gente registrada em textos escritos. A arqueologia infere no comportamento 
humano, e também ideias, a partir de materiais remanescentes do que pessoas fizeram e usaram, e do impacto físico de sua presença no meio ambiente. A interpretação dos dados arqueológicos depende da compreensão de como os seres humanos se comportam no presente e, em particular, de como esse comportamento reflete na cultura material (TRIGGER, 2004, p. 19).

Nesse sentido, o estudo em tela no contexto da paisagem do Sítio Arqueológico Rosário busca, por meio da análise da cadeia operatória de produção da cerâmica, compreender o Sistema Regional de Ocupação de Grupos Agricultores Indígenas do Norte do Estado de São Paulo. Para essa região, tem-se constatado a presença da cerâmica da Tradição Aratu-Sapucaí, associada aos grupos indígenas Caiapó, tendo em vista que, para produzir a cerâmica, o indígena buscou na paisagem a argila, o antiplástico, madeiras para a queima da cerâmica entre outros materiais que o interessaram. A análise do material arqueológico inicia-se pela investigação da matéria--prima na área do sítio arqueológico.

Nessa perspectiva, Anschuetz, Wilshusen e Scheik (2001) defendem que as pessoas projetam a cultura na natureza.

Paisagens, afinal das contas, são as interações dinâmicas de natureza e cultura, não apenas uma imposição superficial da cultura na natureza. Cada grupo introduz seus próprios padrões de ocupação material e não material, adicionando camadas aos traços materiais de utilização anterior ou contemporânea por outros grupos culturais (ANSCHUETZ, WILSHUSEN E SCHEIK, 2001, p. 28).

De acordo com os autores, os arqueólogos têm apresentado contribuições significativas com relação à produção tecnológica em determinada paisagem. Nesse contexto, a arqueologia da paisagem, numa relação direta entre Arqueologia e Geografia, busca esclarecer questões da ocupação do homem no espaço geográfico no passado.

\section{METODOLOGIA}

Em relação à cultura material, o Sítio Arqueológico apresentou em sua área, grande quantidade de material arqueológico, todos de natureza cerâmica, sendo analisados no Laboratório de Arqueologia Guarani (LAG), sob a orientação da Doutora Neide Barrocá Faccio.

Do ponto de vista metodológico, os objetos cerâmicos coletados no sítio foram analisados por meio da cadeia operatória, metodologia de pesquisa utilizada no estudo das ocupações ceramistas do Oeste Paulista 
(FACCIO, 1992; 2011).

O pressuposto básico é tomar o vasilhame cerâmico enquanto unidade de estudo (...). No entanto, na arqueologia brasileira, a grande maioria do material cerâmico é coletado na forma de fragmentos, sendo raros os vasos que conseguem ser recuperados inteiros. Assim, o encaminhamento proposto é agrupar os fragmentos provenientes de um mesmo vasilhame através de análises de sua distribuição na área do sítio, dos planos de fratura e dos diferentes atributos tecnológicos e estilísticos (características da pasta, decoração, forma e dimensões) (FACCIO, 1992, p. 82).

A análise do fragmento de cerâmica pelo viés da cadeia operatória visa entender a vasilha como o objeto, tendo o objetivo de compreender sua função social, mediando a relação entre o homem e a cultura. Nesse contexto, a análise da indústria ceramista do Sítio Rosário, teve por objetivo entender esse artefato em sua totalidade, desde o início da produção, com a escolha da matéria-prima pela oleira, entendendo o seu fabrico, seu uso e sua função, a reciclagem, e o descarte da vasilha na paisagem, pondo fim ao processo de cadeia operatória do artefato, cuja cadeia, segundo Silva (2002), se define como uma série de operações envolvidas em qualquer transformação da matéria, (incluindo o próprio corpo) por seres humanos.

Além disso, do ponto de vista conceitual, esses objetos recebem o nome de artefatos, entendidos como mediador cultural nas atividades humanas. Para Funari (2006), "o artefato, por outro lado, não é apenas um indicador de relações sociais, mas, enquanto parte da cultura material, atua como direcionador e mediador das atividades humanas" (FUNARI, 2006, p. 33).

Em relação à produção dos artefatos pelos grupos humanos pretéritos, La Salvia e Brochado (1989), dizem que:

A confecção de um artefato é o início de um processo de produção que concluído continua em fase de utilização e, ao quebrar-se, encerra uma sequência de funções não específicas, mas presentes dentro de um contexto cultural que ao arqueólogo cabe explicar através da análise de seus fragmentos. É todo um ciclo, visível, se se tenta refazer o sistema, invisível se se observar apenas seus fragmentos representações (LA SALVIA; BROCHADO, 1989, p. 5).

De maneira geral, a cultura material é um elemento importante para a compreensão das sociedades pretéritas, pois, por meio desse elemento pode-se reconstituir a organização espacial, 
tecnológica e cultural do grupo estudado. Além de que, sempre esteve presente na trajetória humana, tendo o papel de transmitir e resguardar o conhecimento das pessoas em seu ambiente natural e social.

Nesse contexto, foram analisadas as seguintes categorias de análise:

1) Técnica de manufatura: nessa categoria foi analisada a técnica ou técnicas utilizadas para a produção do utensílio;

2) Antiplástico: em que se investigou a presença de antiplástico tais como: areia, carvão mineral, caco moído e outros;

3) Espessura da parede das vasilhas: nessa categoria foram tomadas as medidas de espessura da peça com um paquímetro;

4) Tipo de decoração: em que se analisou a presença de decoração plástica ou pintada

5) Forma das vasilhas: a partir da reconstituição de fragmentos de borda, foram feitas reconstituições da vasilha, baseando-se em cálculos matemáticos.

Quanto à análise da paisagem foram verificadas: forma de implantação, fontes de matéria-prima e o que mais dissesse respeito à pesquisa.

\section{RESULTADOS E DISCUSSÕES}

A forma de implantação do Sítio Rosário na paisagem, bem como os materiais produzidos na área desse sítio apresentam similaridade com outros sítios da Tradição
Aratu-Sapucaí do norte do Estado de São Paulo. A tradição Aratu foi identificada por Valentin Calderón (1969/1970), após prospecções realizadas na Bahia, Sergipe e Pernambuco. A origem do nome "aratu" deve-se ao Sítio Arqueológico Guipe, localizado no centro industrial do Município de Aratu, próximo a Salvador, BA. Apesar de esse sítio haver sido destruído após a construção da barragem do Riacho Guipe, Calderón realizou um trabalho de salvamento na área.

Fernandes (2001) reitera a afirmação dizendo que:

A Tradição Aratu foi identificada por Valentim Calderón no Relatório Anual do PRONAPA referente ao ano de 1969/70 e diz respeito à Fase Itanhé da região do Recôncavo Baiano até o Rio Mucuri, no sul do Estado da Bahia. Posteriormente Celso Perota mesclou a esta fase a Fase Itaúnas, por ele identificada em toda a faixa litorânea do Estado do Espírito Santo, em 1968/69 (FERNANDES, 2001, p.21).

Em contrapartida, a Tradição Sapucaí foi identificada por Dias Júnior, em 1969/70 no Estado de Minas Gerais, com o descobrimento das Fases Ibirici e Jaraguá (FERNANDES, 2001) no contexto pronapiano. Todavia, a articulação das tradições em um sistema de povoamento pré-histórico deu-se 
por meio das características tecnológicas da produção de cultura material, conforme Fernandes (2001).

A identificação da Tradição Aratu-Sapucaí foi somente reconhecida com pesquisas desenvolvidas no Estado de Goiás por Schmitz (Schmitz, 1978; Schmitz et al., 1982: Schmitz \& Barbosa, 1985), que identificou tanto a Tradição Aratu (Fase Massâmedes), quanto a Tradição Sapucaí (Fases Itaberaí e Tejuaçu). A Fase Aratu começou a tomar forma nos anos de 1968/69, com a identificação de 24 sítios no Recôncavo Baiano. Lá, segundo Calderón foi possível caracterizar a cerâmica e os padrões de sepultamento desta fase, além de caracterizá-la como sendo de um grupo semipermanente, já coletor, com uma agricultura incipiente, conforme atesta a documentação cerâmica. O material lítico, no entanto, foi abundante e o autor destaca o que foi chamado de quebra-coco. o material lítico associado à Tradição Aratu-Sapucaí está intimamente relacionado ao tamanho das aldeias, geralmente descritas como extensas e estáveis (FERNANDES, 2001, p. 21).

De modo geral, o Sistema AratuSapucaí é identificado por meio de algumas características referentes aos elementos de cultura material, como "as urnas piriformes e a documentação cerâmica bem característica, com fusos perfurados, vasos geminados (duplos), vasilhames de bordas onduladas e fragmentos cerâmicos lisos. Quanto à indústria lítica, os grandes representantes desta tradição são os quebracocos, lascas iniciais e lâminas de machado polidas" (FERNANDES, 2001, p. 30).

Portanto, esse sistema pré-histórico espalha-se pelo Brasil Central e por outros Estados do território, tais como, Bahia, Piauí, Alagoas, Sergipe, Espírito Santo, Minas Gerais e São Paulo. O sistema de povoamento Aratu-Sapucaí decorre da união das tradições Aratu e Sapucaí que foram identificadas por Calderón (1969) como Aratu na Bahia e por Dias (1978) em Minas Gerais como Sapucaí.

Os índios associados a esse sistema de ocupação estabeleciam suas moradias nas encostas e topos de morros próximos a pequenos córregos e rios. Ocupações da Tradição Aratu-Sapucaí não são encontradas em áreas próximas a grandes cursos d'água. De acordo com Júnior (2006), a cerâmica do sistema Aratu-Sapucaí

se caracterizaria por
vasilhames piriformes e
globulares de variados
tamanhos, destacando-se
grandes potes para
armazenagem de líquidos e
grãos, urnas funerárias,
pequenas vasilhas
geminadas, rodelas de fuso
que atestam a fiação do
algodão, cachimbos, além


de pratos e tigelas (JÚNIOR, 2006, p. 18).

Por estar localizado em área de plantio de monocultura de cana-de-açúcar o estado de conservação do sítio foi considerado ruim. O método de resgate dos vestígios arqueológicos foi o de coleta de superfície após sucessivas aragens (ARAÚJO, 2009). As coletas foram realizadas com georreferenciamento (Foto 1).

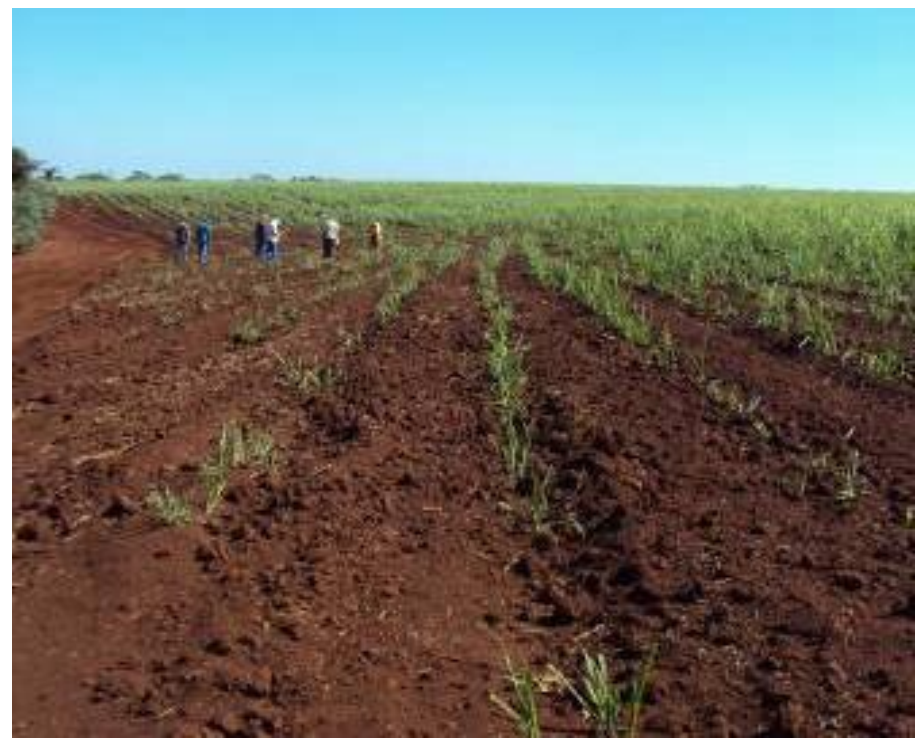

Foto 1. Realização do caminhamento sistemático de superfície na área do Sítio Rosário. Município de Guaíra, SP.

Fonte: Faccio (2012).

Durante a coleta de superfície e as intervenções de subsuperfície foi encontrado um número reduzido de peças arqueológicas (Fotos 2 e 3).
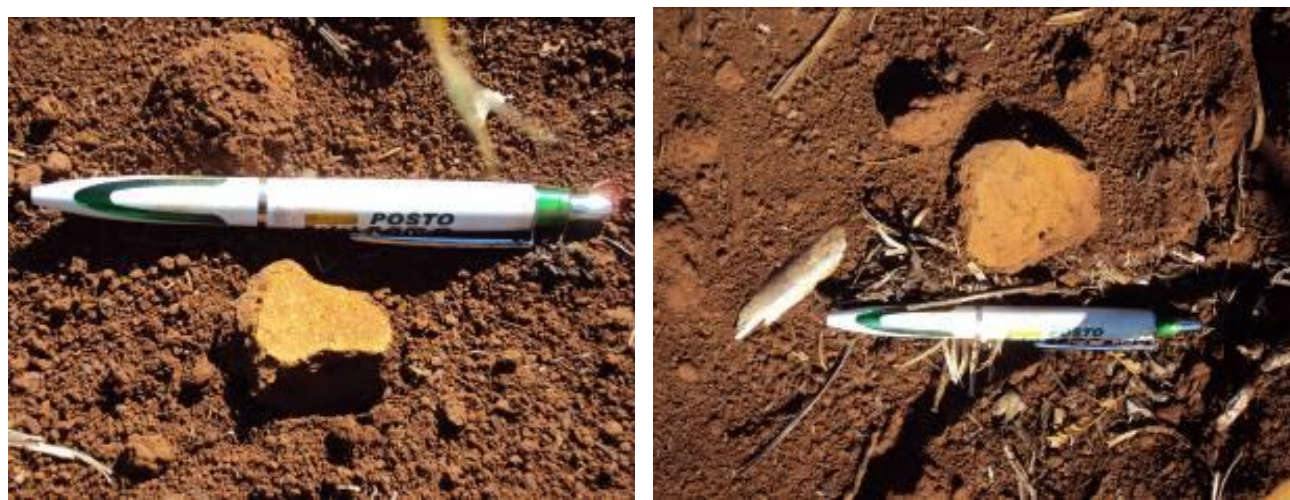

Fotos 2 e 3. Fragmento de cerâmica em superfície na área do Sítio Arqueológico Rosário. Município de Guaíra, SP.

Fonte: Faccio (2012). 
Após mapeamento da dispersão das peças arqueológicas encontradas na área do Sítio Rosário, pudemos caracterizá-lo como um sítio de pequeno porte, com 794 fragmentos de cerâmica.
No quadro 1, apresentamos as classes de peças evidenciadas no Sítio Arqueológico Rosário. Foram identificadas as classes parede, borda, base e um fragmento de vaso conjugado, totalizando 794 fragmentos.

Quadro 1: Frequência de classes do material cerâmico do Sítio Arqueológico Rosário

\begin{tabular}{|c|c|}
\hline Classes & Quantidade de peças \\
\hline Base & 72 \\
\hline Borda & 42 \\
\hline Parede & 677 \\
\hline Parede de vaso conjugado & 1 \\
\hline Total & 794 \\
\hline
\end{tabular}

Fonte: Faccio (2012).

Dos 794 fragmentos de cerâmica encontrados na área do Sítio Arqueológico Rosário, 677 são paredes, 72 bases, 42 bordas. Apenas um fragmento foi classificado como parede de vaso conjugado. Esse tipo de vaso é característico da Tradição Aratu-Sapucaí do norte do Estado de São Paulo. Ainda é característica da Tradição Aratu-Sapucaí o tipo liso na face interna e externa das vasilhas. O Sítio Rosário apresentou maioria do tipo liso. Somente 19 peças apresentaram engobo branco ou vermelho. Em todos os fragmentos analisados foi identificada a técnica de manufatura de rolete, que é a mais difundida entre as tradições e culturas indígenas brasileiras.
Para a confecção dos vasilhames foi utilizado, predominantemente, o antiplástico mineral associado ao caco moído (636 peças ou $80,1 \%$ dos casos). O antiplástico mineral foi identificado em 157 (19,8\% dos casos). O uso do mineral associado ao cariapé esteve presente em uma peça.

A pasta utilizada na cerâmica do Sítio Arqueológico Rosário foi plástica em $36,52 \%$ dos casos, intermediária em $24,81 \%$ dos casos e dura em $38,66 \%$ dos casos. A espessura das paredes das peças variou entre 0,4 e $3,0 \mathrm{~cm}$, sendo que as bases apresentaram as maiores espessuras. 0 tamanho do antiplástico mineral e do caco moído variou entre 0,1 e 1,3 cm. 
As fotos 4 e 5 apresentaram dois fragmentos de bordas identificados no Sítio em questão e, a partir dessas duas bordas, foi
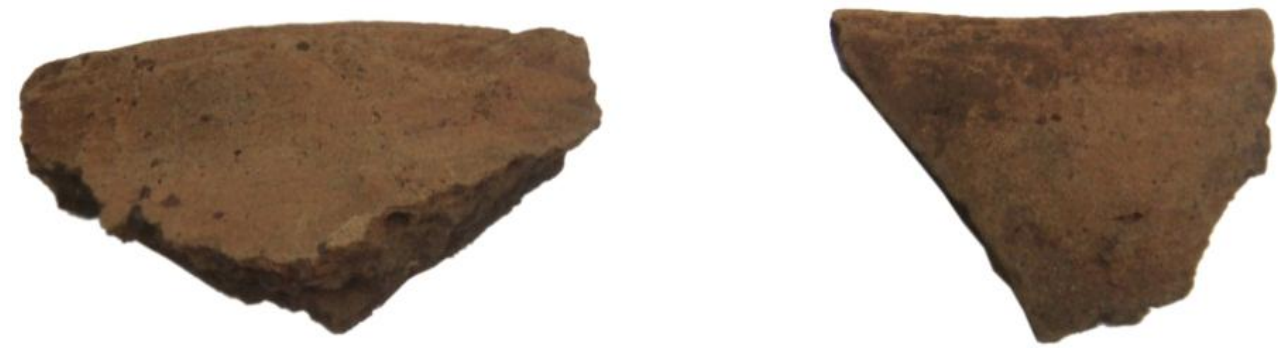

Fotos 4 e 5. Bordas do Sítio Arqueológico Rosário. Município de Guaíra, SP.

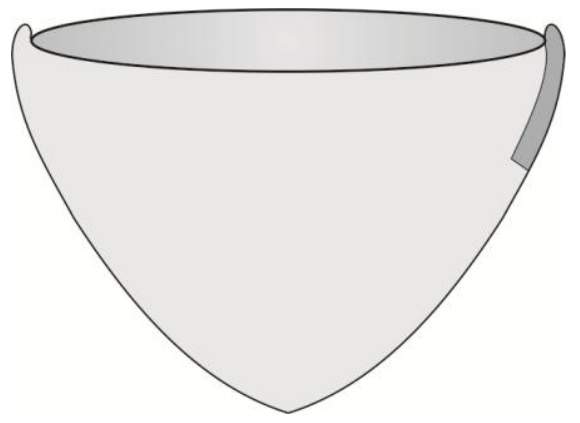

Figura 2. Vaso profundo de boca constrita. Contorno infletido direto interno. Sítio Rosário, Município de Guaíra, SP.

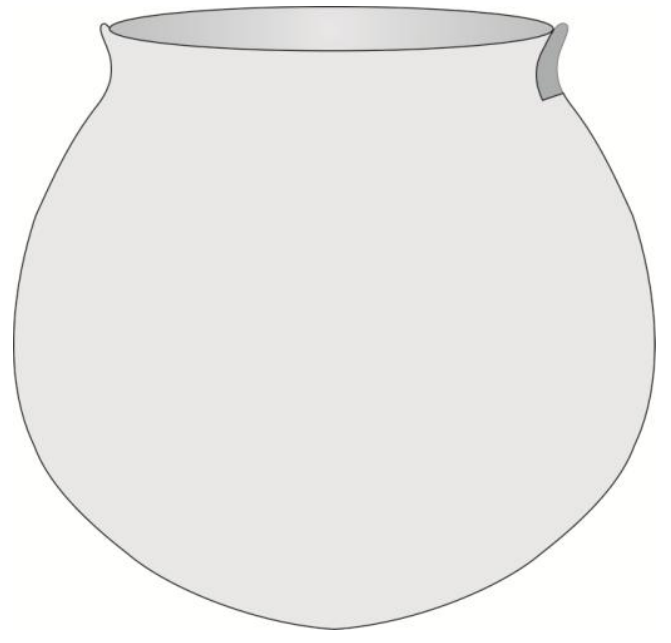

Figura 3. Vaso profundo de boca constrita. Contorno extrovertido inclinado interno. Sítio Rosário, Município de Guaíra, SP. 
O Sítio Rosário foi localizado em vertente de uma colina aplainada, de suave inclinação. Sua cota batimétrica é de aproximadamente 510 metros em relação ao nível do mar. A área em que foi localizado o Sítio Arqueológico Rosário faz parte da Bacia Hidrográfica do Baixo Pardo/Grande. Encontra-se próximo a área de curso d'água de pequeno porte, o que constitui característica de sítios associados à Tradição Aratu--Sapucaí.

\section{CONSIDERAÇÕES FINAIS}

A cultura, como a totalidade da experiência adquirida é a soma de conhecimentos acumulados pelo homem que são transmitidos socialmente, como uma herança social. Portanto, a cultura é cumulativa e dinâmica, pode ser imaterial, como a música e o folclore ou material, como os monumentos. Ela se manifesta no cotidiano, nos costumes, hábitos e ações de um povo. Nesse trabalho apresentamos o estudo da coleção cerâmica e da paisagem do Sítio Arqueológico Rosário, numa relação direta entre cultura e meio ambiente. Nosso objetivo foi analisar o modo de ocupação dos grupos humanos que habitaram o espaço, onde se insere o sítio arqueológico, analisando, além de artefatos arqueológicos, o contexto ambiental que permeia o sítio.

Não foi possível reconstituir vasilhas inteiras uma vez que as peças estavam bastante fragmentadas. A fragmentação e destruição das vasilhas cerâmicas do sítio deve-se ao uso de máquinas como o arado e subsolador que foi utilizado, na região, para o cultivo da monocultura da cana-de-açúcar.

Para entendermos o estabelecimento de grupos pretéritos na região, recorremos à Arqueologia e à Geografia, ciências que dispõem da cultura material e do contexto ambiental, para explicar e narrar os acontecimentos de ordem humana. Nesse sentido, vimos que o Sítio Rosário como outros sítios do Norte do Estado de São Paulo apresentam características ambientais e culturais ligadas aos grupos indígenas Aratu-Sapucaí.

Dessa forma, este trabalho representa uma contribuição para o conhecimento de características relevantes do Sistema Regional de Ocupação de Grupos Agricultores filiados à Tradição Aratu, que habitaram a região norte do Estado de São Paulo num passado pretérito.

\section{REFERÊNCIAS}

ANSCHUETZ, K. F.; WILSHUSEN, R. H.; SHEICH, C. L. Uma Arqueologia de paisagens: perspectivas e direções. Journal of Archaeological Research, vol. 9, n. 2, 2001. Traduzido por Samara Diva Ferreira Marcos.

CALDERÓN, V. Contribuição para o Conhecimento da Arqueologia do Recôncavo e do Sul do Estado da Bahia. Museu Paraense Emílio Goeldi. - Pará, 1968. (Série Arqueologia). 
FACCIO, N. B. Estudo do Sítio Arqueológico Alvim no Contexto do Projeto Paranapanema. 1992. Dissertação (Mestrado em Arqueologia) - FFLCH, Universidade de São Paulo. São Paulo.

FERNANDES, S. C. G. Contribuição para o Estudo da tradição Aratu-Sapucaí Estudo de Caso: O Sítio Arqueológico de Água Limpa, Monte Alto - São Paulo. Revista de Arqueologia Canindé, Xingó, n. 1, dezembro, 2001.

FUNARI, P. P. A. Arqueologia. São Paulo. Contexto, 2006.

JÚNIOR, G. H. P. - Arqueologia Regional da Província Cárstica do Alto São Francisco: um estudo das tradições ceramistas Una e Sapucaí. Dissertação (Mestrado em Arqueologia) - MAE/Universidade de São Paulo. São Paulo, 2006.

LA SALVIA, F; BROCHADO, J. P. Cerâmica Guarani. Porto Alegre, Posenato Arte e Cultura, 1989.

MORAIS, J. L. Arqueologia da Região Sudeste. Revista USP, São Paulo, n. 44, p. 10-31, dez./fev., 1999/2000.

PALLESTRINI, L.; MORAIS, J. L. Arqueologia Pré-histórica Brasileira. São Paulo: Fundo de Pesquisas do Museu Paulista, 1982.

RENFREW, C; BAHN, P. Arqueologia: teorias, métodos y prácticas. Editora Akal, 2007.

ROBRAHN-GONZÁLEZ, E. M. Arqueologia em Perspectiva: 150 anos de reflexão e prática no estudo de nosso passado. Revista USP, São Paulo, n. 44, p. 10-31, dez./fev., 19992000.

ROSS, J. L. S. Geografia do Brasil.. São Paulo: Editora da Universidade de São Paulo. 2006.

SILVA, F. A. A tecnologia e seus significados. In: WORKSHOP ARQUEOLÓGICO DE XINGÓ.
2., 2002. Canindé de São Francisco. Anais... 2002.

TRIGgeR, B. G. História do Pensamento Arqueológico. São Paulo. Editora Odysseus. 2004.

Recebido para publicação em 11/09/2012 Revisado em 23/05/2013

Aceito em 23/01/2014 